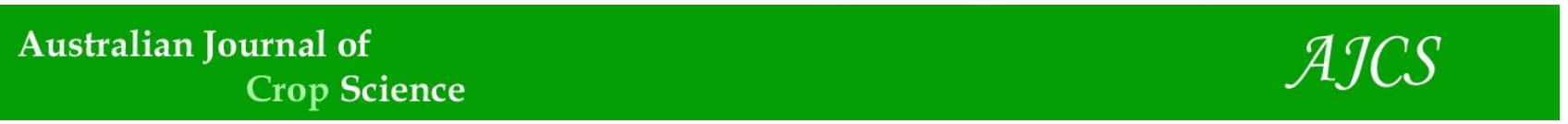

AJCS 14(06):913-922 (2020)

ISSN:1835-2707

doi: 10.21475/ajcs.20.14.06.p1721

\title{
Spatial arrangement of plants on leaf growth and development and the yield potential of soybean
}

\author{
José Eduardo Minussi Winck, Thomas Newton Martin*, Marlo Adriano Bison Pinto, Lucas Allan Bruning, \\ Guilherme de Almeida Arismendi
}

Universidade Federal de Santa Maria (UFSM), Av. Roraima, $n^{\circ}$ 1000, Cidade Universitária, Camobi, Santa Maria - RS.

*Corresponding author: martin.ufsm@gmail.com

Abstract

This study aimed at determining the effect of a variety of plants arrangements on foliar growth and development as well as the productive potential in soybean. The field experiments were performed over two agricultural years (2015/16 and 2016/17) on Argisoil in subtropical environment. The two selected cultivars, viz., BMX Tornado RR and FPS Urano RR were sown in four spatial distribution of the plants such as conventional spacing $(0.45 \mathrm{~m}$ spacing between rows), reduced spacing $(0.225 \mathrm{~m}$ spacing between rows), paired spacing (two rows with $0.225 \mathrm{~m}$ and $0.45 \mathrm{~m}$ spacing from the other rows) and crossed spacing ( $0.45 \mathrm{~m}$ spacing between the rows with crosses of two rows, at a $90^{\circ}$ angle). The randomized block design was adopted for the experiments with the treatments in a $2 \times 4$ factorial distribution and four replications. The first factor was the cultivar and the second types of plant distribution. The results showed that plant arrangement affected the plant profile regarding the behavior of the ecophysiological variables like plastochron, leaf lifetime and yield distribution. Leaf life in each stratum was caused by the foliar senescence rhythm, explained by a 4th degree polynomial model, revealing two peaks in the senescence rate, one during pre-flowering stage and the other when the grain filling stage was completed. According to the results, we do not recommend changes in conventional spacing.

Keywords: Glycine max (L.) Merr.; leaf area index; senescence; lifetime, yield potential.

Introduction

Productivity in soybean is controlled partially by the capacity of the plants to capture the solar energy and convert it into dry matter via photosynthesis (Rocha et al., 2017). Therefore, leaf area integrity is significant specifically during the reproductive phase. At this stage, the photoassimilates become crucial for the formation of the reproductive structures, particularly the production of the grain partition (Rocha et al., 2017).

Any decrease in the leaf area may negatively affect the plant growth and development, inducing changes in the activity of dry matter accumulation, thus lowering the yield. The effective utilization of the available radiation by the soybean is expressed as the maximum absorption of the photosynthetically active fraction by the photosynthetic tissues, chiefly the leaves. Thus, leaf emission rate (plastochron), leaf number, size and senescence rate of the plant can determine the leaf area (AF) (Setiyono et al., 2011; Richter et al., 2014; Tagliapietra et al., 2018). The leaf area and the senescence rate of the plant are strongly linked to the carbon accumulation.

To alter the plant architecture and maximize the leaf area index (LAI) of the modern cultivars during their reproductive stages, many techniques have been adopted such as the decrease in the spacing of the rows (Jaybhaye et al., 2015; Balbinot Junior et al., 2018), cross-sowing (Santos et al., 2015; Ferreira et al., 2018; Souza et al., 2018) and sowing in paired rows (Bruns, 2011; Procópio et al., 2014; Balbinot Junior et al., 2018). The rise in grain yield in response to such plant arrangements has been ascribed to the greater interception of radiation by the leaves per unit area. Therefore, assessing the contribution of each stratum of the canopy and the influence exerted by the smallest shading in the leaf life span becomes significant. Some authors report longer duration of the foliar area during the reproductive period when lesser spacing is used with more number of days of maximum interception of solar radiation (Rahman et al., 2013; Zhou et al., 2011).

The phyllochron-controlled rhythm appears to be linked to the initiation, expansion, senescence and abscission of the leaf. This linkage is useful in correlating the dynamics of successive nodal leaf growth with the temporal canopy development pattern (Setiyono et al., 2011). Careful evaluation of the size and lifespan of each trifolium of the soybean plant necessitates a broader explanation of the IAF dynamics of the canopy, and deeper understanding of the IAF dynamics both for model improvement as well as crop growth and development. The variations observed in the foliar architecture are a powerful indicator for crop management and to produce good canopy structures (Setiyono et al., 2011).

There are few works in the literature that aim to understand the determination of the productivity components in function of the morphological characteristics under different management of the soybean architecture (Kantolic et al., 2007; Setiyono et al., 2011; Zanon et al., 2016; Ferreira et al., 2018) and works that define the rate senescence of leaves in 
soybean are absent. In this sense, we aimed to evaluate the influence of plant arrangement on leaf growth and development and yield of soybean crop.

\section{Results and discussion}

\section{Meteorological conditions}

The soybean crop cycle was characterized by good rainfall distribution, which supported the soybean development, over the two evaluation years.

\section{Final number of nos and plastochron}

The NN showed differences among the cultivars (Table 1), with the higher values in the cultivar BMX Tornado RR. However, in the crossed spacing, both cultivars revealed lower NN values, when compared with the other arrangements of plants. The higher plastochron values for the crossed spacing indicated a longer interval in the emergence of two consecutive nodes, which implied that the lower NN is caused by the sensitivity of the plant to the photoperiod to stimulate the plant to flower and restrict the vegetative phase. Thus, NN is a variable that is useful for the indirect selection in soybean as it shows a high correlation with grain productivity (Egli et al., 2013).

For all the treatments, irrespective of the year, the regression noted between NN and STa gave a value of 0.99 for the coefficient of determination. This is an important condition, because for node emission the determining meteorological variable is air temperature (Sinclair, 2005). The plastochron value showed no difference between the cultivars, revealing an average of $59.19^{\circ} \mathrm{C}$ day for 2015/16 and $59.99^{\circ} \mathrm{C}$ day for $2016 / 17$. However, in the present study, for the same cultivar and sowing date, the plastochron revealed variations depending on the spacing maintained between the rows at sowing. This was probably due to occurrence of more intense intraspecific competition by radiation when the crop was sown in less spacing between the rows.

\section{Leaf area index and rate senescence leaf}

The paired and reduced spacings produced higher LAl in the main stem, irrespective of the cultivar evaluated. However, in the cultivar BMX Tornado RR, higher LAI was registered in the branches. The leaf expansion presented the highest values at the commencement of the developmental cycle in the cultivar FPS Urano RR. However, during the time from stages R1 to R5, a lower LAl evolution was seen with the reduced spacing (Figures 1 and 2). Higher LAI values at the commencement of the cycle are significant because they cause the interception of solar radiation, and thus enable a greater production of photoassimilates (Zhou et al., 2011). This evolution recorded for the IAF registered maximum value almost at the R5 stage, concurring with the findings of Tagliapietra et al. (2018).

Table 2 lists the differences in the leaf lifespan among all three canopy and cultivar strata. In 2015/16 the cultivar FPS Urano RR displayed longer leaf life in the upper stratum, whereas in the middle stratum this phenomenon was not observed only for the crossed-treatment. In 2016/17 the differences among the cultivars was noticeable only in the middle stratum, and when compared with the conventional and reduced spacing, the values for the BMX Tornado RR were higher. The upper leaves of the neighboring plants may affect the lower stratum. The useful life of the leaves of the lower stratum is shorter and is limited by the shading of the leaves of the upper stratum. In the leaves of the middle stratum of cultivar BMX Tornado RR and those of the middle and upper strata of cultivar FPS Urano RR, the source / drain relationship in the knot region also appears to exert some degree of influence. The main stem knots raised to the branches revealed earlier leaf senescence, while the nodes had a high photosynthetic demand (leaf and flower output in the leaf axilla). They maintained their leaves in an active state for a longer duration. The cultivar BMX Tornado RR with indeterminate growth type (TC) revealed higher competition for photoassimilates between the upper stratum leaves emitted after R1 and the fixation of the plant reproductive structures. This is the most likely reason for the indeterminate cultivars to possess leaves with shorter life (Supplementary Figures 2-3) and smaller size than others, particularly at the canopy top as evident in the BMX Tornado RR cultivar. This differentiation in indeterminate cultivars with respect to the upper leaves makes the plants look more pyramidal in shape. This may promote the solar radiation to penetrate into the middle stratum leaves of the canopy and the phytosanitary products for disease and insect control (Setiyono et al., 2011). The trifolium size pattern was evident in the soybean plant profile (Supplementary Figures 4-5), which revealed a similar trend to the one reported by Setiyono et al. (2011). They showed higher leaf size values for the 8th node of the main stem and a gradual decrease towards the direction of the plant apex. The conventional spacing, for both cultivars, generated the highest average leaf size in the main stem $\left(133.44 \mathrm{~cm}^{2}\right)$, while the crossed spacing registered the lowest value $\left(109.13 \mathrm{~cm}^{2}\right)$. The cultivar FPS Urano RR showed a higher leaf size value $\left(141.48 \mathrm{~cm}^{2}\right)$ than BMX Tornado RR $\left(107.85 \mathrm{~cm}^{2}\right)$, regardless of the spacing. This trait of BMX Tornado RR support plant against incidence of diseases is favorable, as it may permit greater penetration of the phytosanitary products to the canopy interior. However, it is of less use under conditions of low radiation incidence (Taiz et al., 2017). Two peaks were obvious for the leaf senescence rate curve on the main stem (Figures 3 and 4). The first during the pre-flowering phase (R1) and the second, when grain filling was completed (R6). The photosynthetic action was seen to support the grain filling and plant reserve translocation (Rocha et al., 2017) and may rank among the factors that induce foliar senescence. The leaf senescence rhythm for the cultivars investigated can be explained by the 4 th degree polynomial model (Figure 5). This data can prove beneficial to the producer, as it can be incorporated in planning the practices of phytosanitary management, e.g. in determining the best times for fungicide application.

\section{Yield potential}

From the results of the grain yield potential in each plant stratum, the first peak in the leaf senescence rate curve can be assumed to have occurred around the R2 phase, which resulted in the reproductive structures of the plant bottom stratum being aborted (Figures 6). At this developmental stage, the leaf area becomes crucial as the photoassimilates are highly essential for the reproductive structures to be formed. 
Table 1. Number of nodes (NN), plastochron $\left({ }^{\circ} \mathrm{C}\right.$ day leaf-1) and coefficient of determination of the plastochron $\left(\mathrm{R}^{2}\right)$ for the four spacings between the rows.

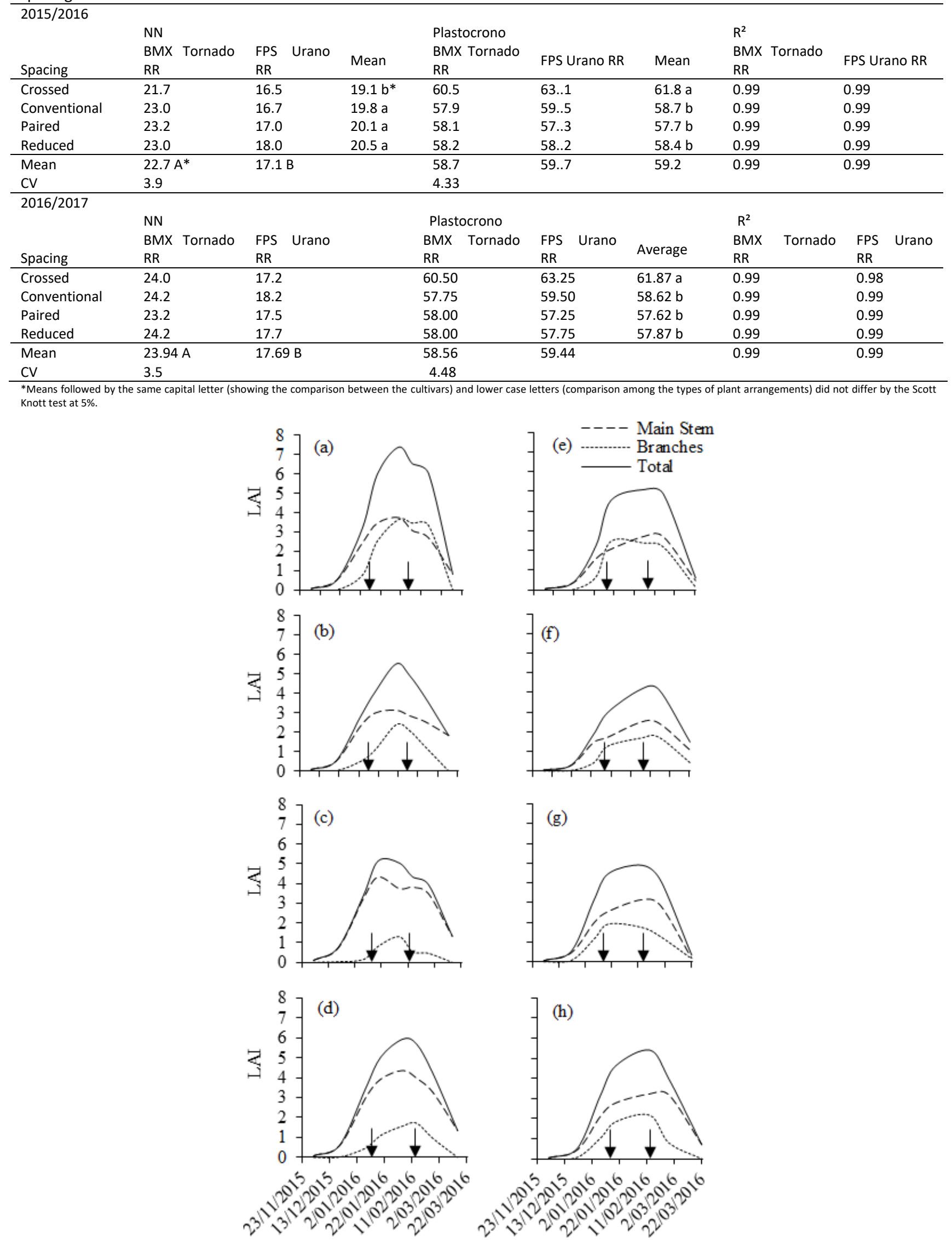

Fig 1. Evolution of leaf area index of soybean cultivars FPS Urano RR(a,b,c e d) and BMX Tornado RR (e,f,g and h) at conventional row spacings ( $a$ and e), crossed ( $b$ and f), paired ( $c$ and $g$ ) and reduced ( $d$ and $h$ ) in the agricultural season 2015/16. The arrows indicate the stages R1 and R5. 
Table 2. Mean leaf life in each stratum of the canopy calculated in thermal sum (으 day) for the cultivars FPS Urano RR and BMX Tornado RR in the different spacings between the rows.

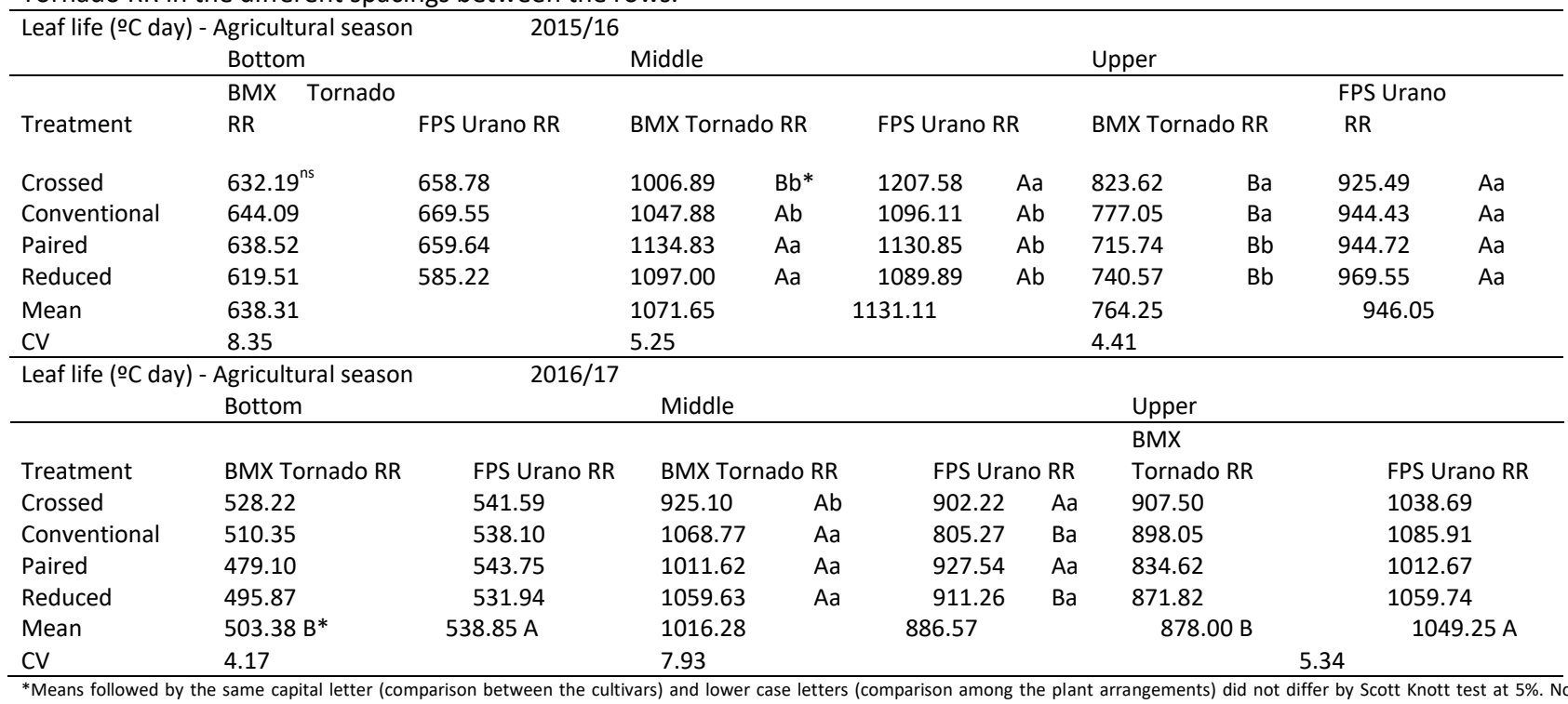

*Means followed by the same capital letter (comparison between the cultivars) and lower case letters (comparison among the plant arrangements) did not differ by Scott Knott test at $5 \%$. Not significant at $5 \%$.
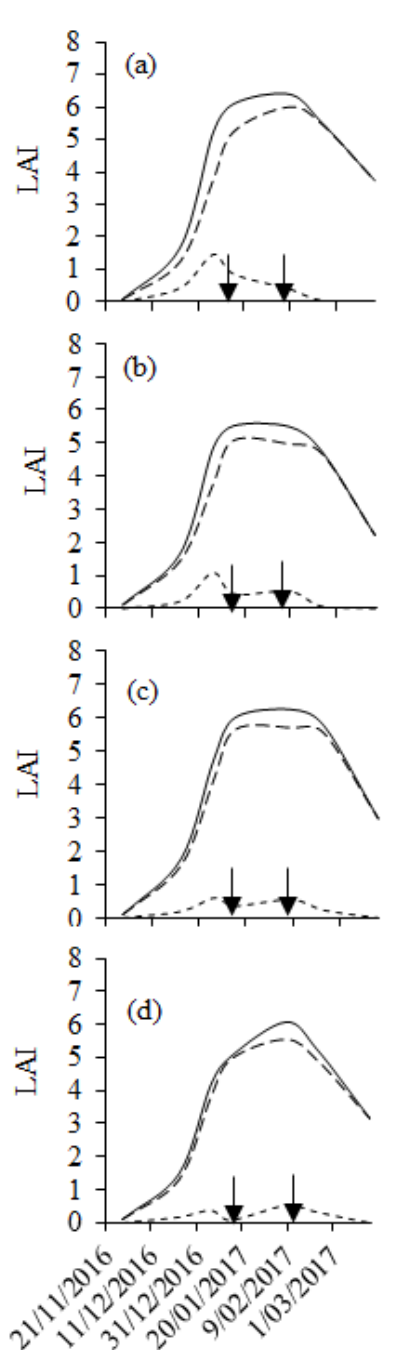

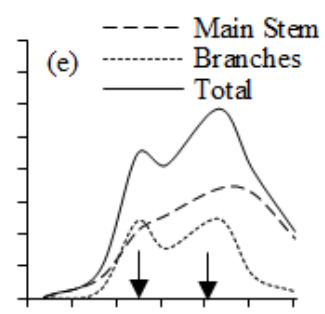

(f)

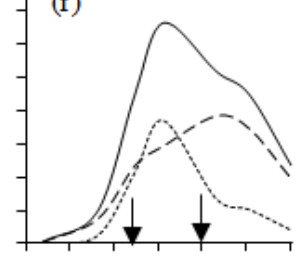

(g)

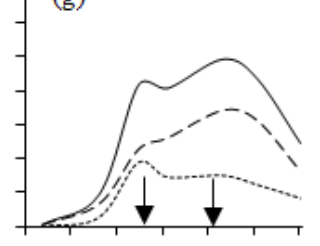

(h)
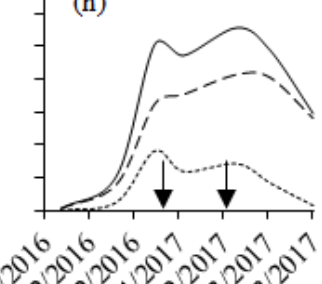

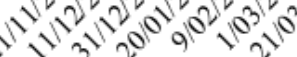

Fig 2. Evolution of leaf area index of soybean cultivars FPS Urano RR(a,b,c e d) and BMX Tornado RR (e,f,g and h) at conventional row spacings ( $a$ and e), crossed ( $b$ and f), paired ( $c$ and $g$ ) and reduced ( $d$ and $h$ ) in the agricultural season 2016/17. The arrows indicate the stages R1 and R5. 

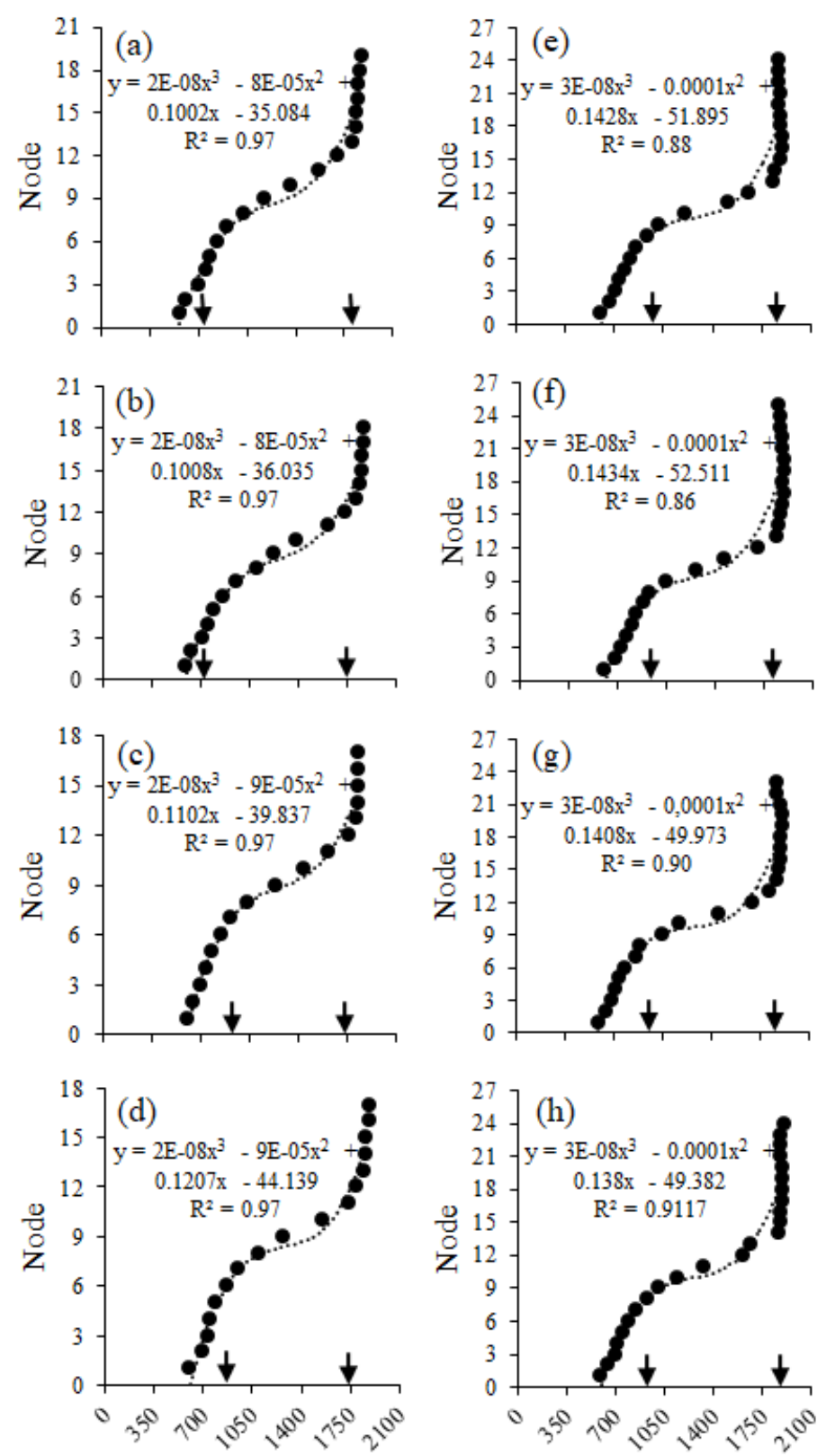

Fig 3. Thermal summation for foliar senescence of the cultivars FPS Urano RR ( $a, b, c$ and $d$ ) and BMX Tornado RR (e, $f, g$ and $h$ ) at conventional spacings ( $a$ and e), cross ( $b$ and f), paired ( $c$ and $g$ ) and reduced ( $d$ and $h$ ) in the agricultural season 2015/16. The arrows indicate the stages $\mathrm{R} 2$ and $\mathrm{R} 6$.

The small internodal translocation of the photosynthetic products implies that the number of pods fixed in each inflorescence is restricted by the photoassimilates produced in this plant region (Ookawa et al., 2005; Nico et al., 2015). Earlier studies performed in the early 2000s reported identical findings. For example, Pires et al. (2005) reported that leaf abscission takes place when the leaves cannot supply adequate amounts of photoassimilates, particularly under conditions of shading, which characterize the bottom stratum. The middle stratum accounted for a large part of the productivity potential during the flowering phases and commencement of grain filling. In the R8 stage, the greatest contributor to the final yield of each plant is the upper canopy stratum, which is responsible for roughly $52 \%$ of the final produced grain. This is because of the higher photosynthetic efficiency of the leaves of the upper stratum, which are younger and able to make the best use of the available sunlight, inducing an average fixation of $87 \%$ of the reproductive structures. The bottom stratum recorded the lowest fixation of the reproductive structures. The low photoassimilate output by the leaves of this stratum during the grain filling phase may most likely have ranked among the factors responsible for this, as most of the leaves in this stratum appeared early enough to cause alterations to the source/drain relationship (Taiz et al., 2017). The BMX Tornado RR cultivar registered a productivity potential in R2 with 1621 and $345 \mathrm{~kg} \mathrm{ha-}{ }^{1}$ higher than cultivar FPS Urano RR, in $2015 / 16$ and $2016 / 17$, respectively. However, $48 \%$ of the reproductive structures were fixed in the Urano RR FPS cultivar and $31.2 \%$ in the $\mathrm{BMX}$ Tornado RR cultivar in $2015 / 16$. The cultivars showed no differences between them in $2016 / 17$ (both 

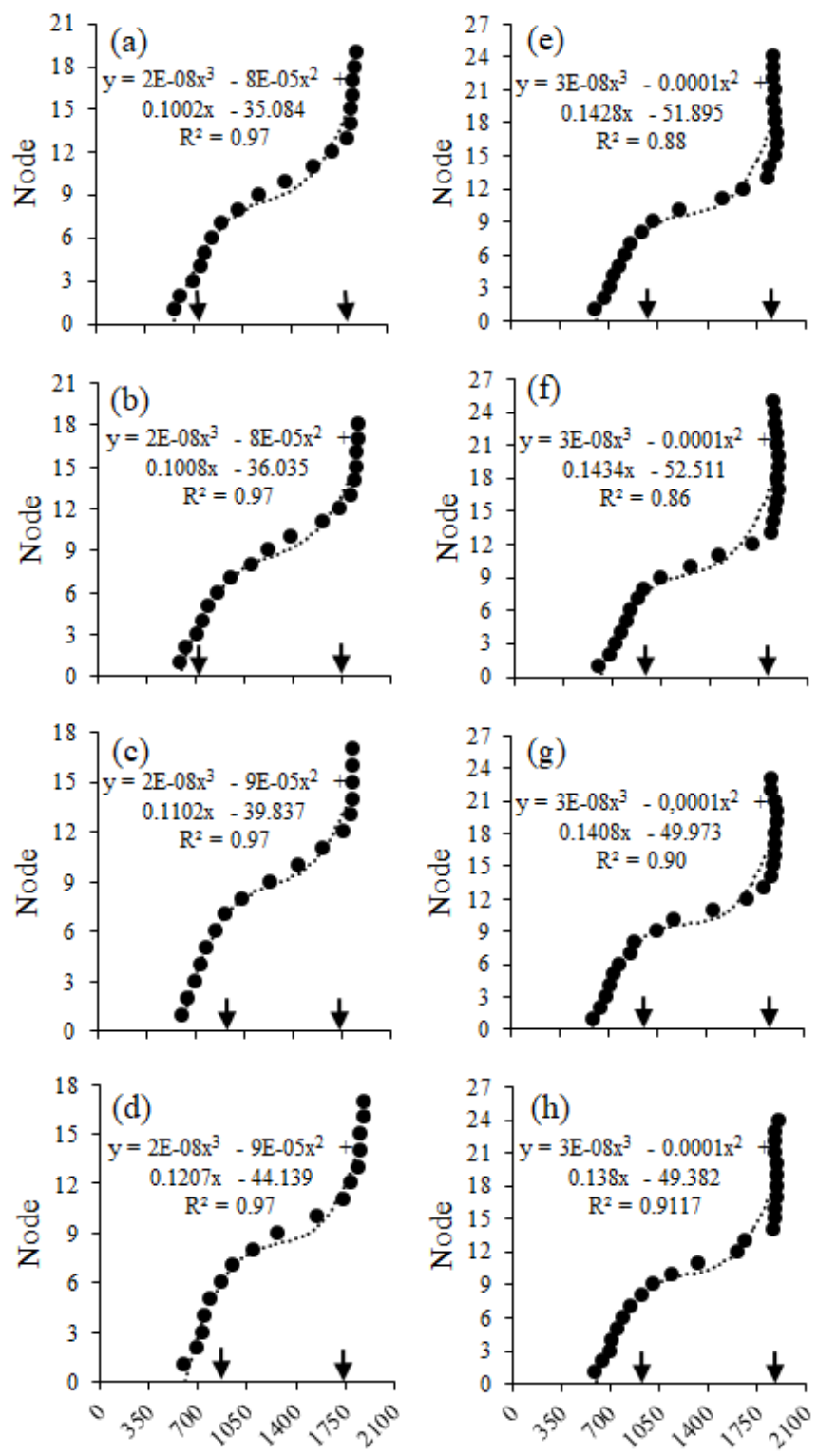

Fig 4. Thermal summation for foliar senescence of the cultivars FPS Urano RR ( $a, b, c$ and $d$ ) and BMX Tornado RR (e, $f, g$ and $h$ ) at conventional spacings ( $a$ and e), cross ( $b$ and $f$ ), paired ( $c$ and $g$ ) and reduced ( $d$ and $h$ ) in the agricultural season 2016/17. The arrows indicate the stages R2 and R6.

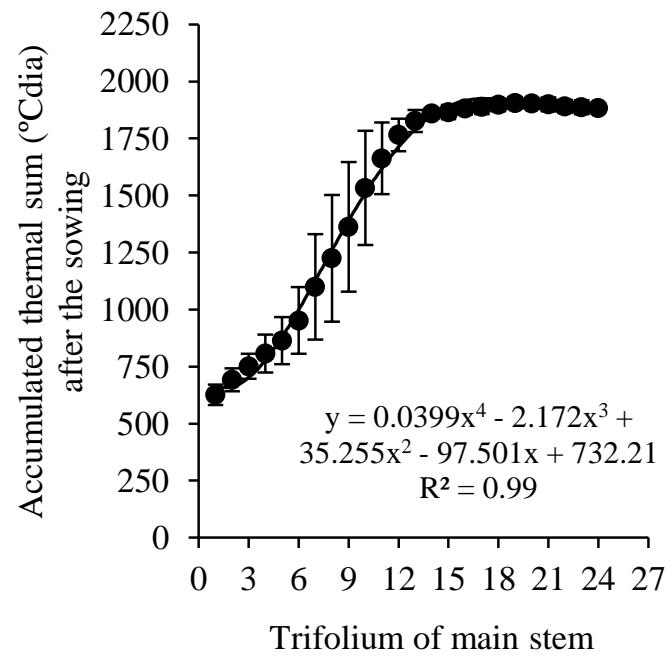

Fig 5. Estimated model for trifolium senescence of the main stem of the soybean plant. 

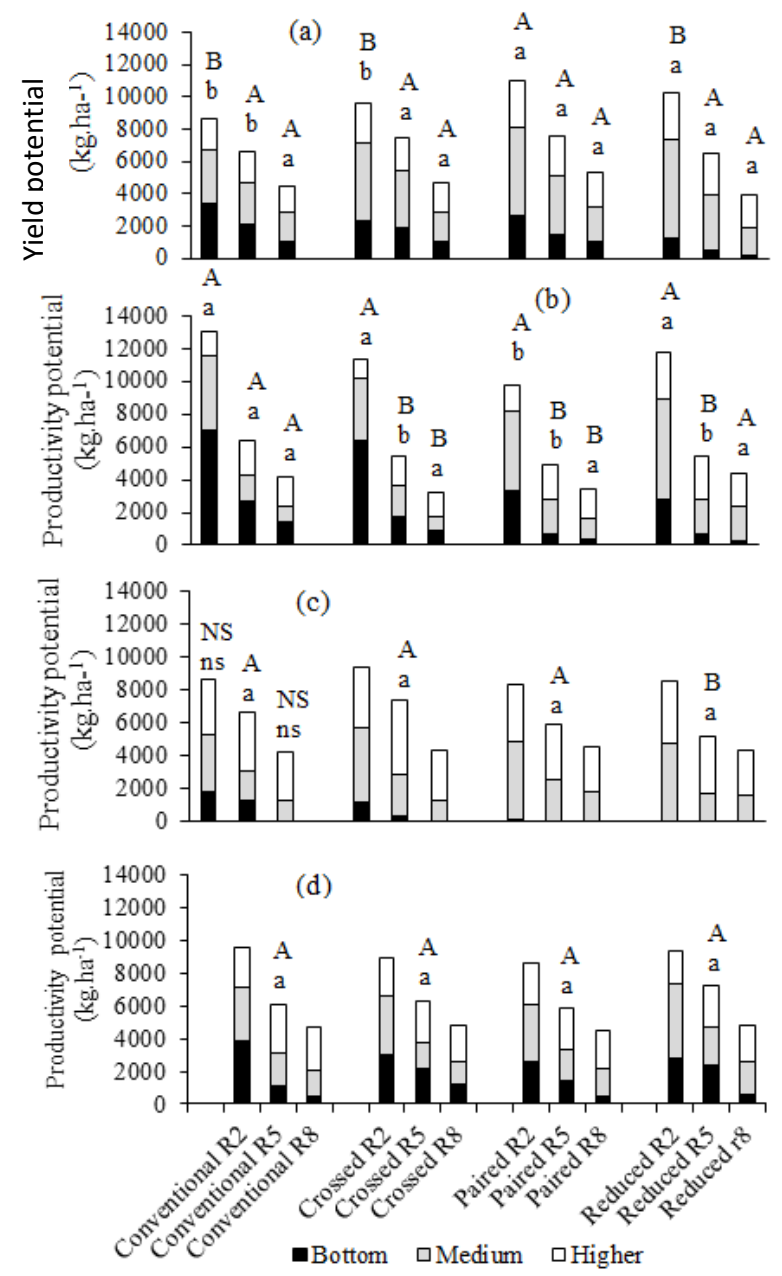

Fig 6. yield potential in R2, R5 and R8 of the cultivars FPS Urano RR ( $a$ and c) and BMX Tornado RR (b and d), in the agricultural season 2015/16 ( $a$ and $b$ ) and 2016/17 ( $c$ and d), for the spaces between rows: conventional, crossed, paired and reduced. *Means followed by the same capital letter (comparison between cultivars) and lower case letters (comparison between spacings) did not differ among themselves by the Scott Knott test at $5 \%$ error probability. ns $=$ not significant.

revealing 50\%). When the competition for the photoassimilates rises between the structures, a low percentage may be seen in the fixation of the reproductive structures, where numerous flowers do not always indicate high productivity (Pires et al., 2005). In the cultivar BMX Tornado RR a drop of 30 to $52 \%$ of the productive potential was observed between the R2 and R5 stages and 49 to $69 \%$ between the R2 and R8. On the other hand, cultivar FPS Urano RR showed a $29 \%$ decrease between the R2 and R5 phases and 50 to $54 \%$ between the R2 and R8. These findings suggest the significance of the management techniques when implemented just after flowering commenced to investigate the productive potential of each cultivar.

The findings from the different plant arrangements in 2015/16 revealed decrease rates of fixation of the reproductive structures in the reduced $(29.5 \%)$ and crossed (28.5\%) spacing for the BMX Tornado RR; and in the reduced spacing $(37.7 \%)$ for the cultivar FPS Urano RR. The reason for these results may be the small degree of fixation of the reproductive structures in the lower stratum of these treatments $(18.5 \%$ in the reduced spacing for the FPS Urano RR and 9.7 and $13 \%$ in the reduced and crossed spacing for the BMX Tornado RR). For the $2016 / 17$ period, no differences were noted among the treatments with respect to the number of reproductive structures fixed in the middle and upper strata. However, the lower stratum revealed $100 \%$ reduction in the number of reproductive structures fixed for the cultivar FPS Urano RR and 60 to $90 \%$ for the BMX Tornado RR treatments.

The upper stratum showed a rise in the productive potential up to the R5 stage for the BMX Tornado RR, caused by the emission of new productive nodes, with indeterminate growth. This growth is distinguished by the vegetative phase overlapping the reproductive phase, soon after the flowering commenced. In the indeterminate cultivars the emission of nodes continues up to the R5 stage (Zanon et al., 2015). Thus, an adjustment is observed in the source / drain relationship, in which the plant must meet the vital need for the requirement of the photoassimilates for nodes emission news, as well as the formation and fixation of the reproductive organs (Setiyono et al., 2011). This finally culminates in a high quantity of flowers being aborted in the middle and bottom strata and the emergence of smaller sized flowers and leaves at the plant apex.

Therefore, changes in conventional spacing are not recommended. Productivity increase can be more easily obtained in conventional spacing where the productive 
potential of the lower third is higher in R2. Agricultural practices such as balanced fertilization and irrigation can assist in the fixation of these reproductive structures. Further studies on plant architecture are needed in early genotypes (GMR <5.5) with high yield potential, which are characterized by low branching capacity.

\section{Materials and methods}

\section{Search location}

The field experiment was conducted in the experimental section of the Plant Science Department of the Federal

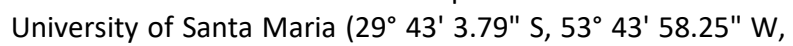
and $95 \mathrm{~m}$ altitude), in the municipality of Santa Maria / RS, over a 2-year period (2015/16 and 2016/17). The site experienced type Cfa climate according to the Köppen classification, which is subtropical and humid, with hot summers and with no well-defined dry season (Peel et al., 2007). The experimental area is characterized by soil of the Arsenic Dystrophic Red Argisoil type (Embrapa, 2013).

\section{Design and experimental conditions}

Two cultivars of the group showing close relative maturity (GMR) and different growth types (TC) were selected. They were the BMX Tornado RR - indeterminate (TC) and GMR 6.3 and FPS Urano RR - determinate (TC) and GMR 6.2. They were chosen based on four types of spatial distributions of plants with no alterations in the plant density, viz., conventional spacing ( $0.45 \mathrm{~m}$ spacing between the rows), reduced spacing ( $0.225 \mathrm{~m}$ spacing between the rows), paired spacing (two rows spaced at $0.225 \mathrm{~m}$ and $0.45 \mathrm{~m}$ apart from the other two rows) and crossed spacing $(0.45 \mathrm{~m}$ spacing between the rows, with crossing of two rows, at an angle of $\left.90^{\circ}\right)$. We adopted the randomized block design with a $2 \times 4$ factorial distribution and four replications, while the first factor consisted of the cultivars and the second four types of plant distribution.

Each experimental unit comprised of five rows of plants extending across an area of $2.25 \times 7.75 \mathrm{~m}^{2}$. Each unit had two lateral rows of $0.5 \mathrm{~m}$ at each end as the border. In the experiments, sowing was done on 11/23/2015 and 11/21/2016 (MAPA, 2015), with a density of 22 plants $\mathrm{m}^{-2}$ for the BMX Tornado RR and 30 plants $\mathrm{m}^{-2}$ for the FPS Urano RR. Carefully adhering to the technical recommendations for the crop, base fertilization, seed treatments, inoculations and weed control were accomplished (Embrapa, 2014). Pest and disease control were performed preventively with insecticides and fungicides being applied seven times throughout each agricultural year.

\section{Evaluations}

The day of emergence was determined when $50 \%$ of the seedlings of the plot showed the cotyledons just above the soil surface. At post-emergence, the plant population was adjusted and manual thinning was done. Finally, five seedlings were randomly marked in each plot, where the number of nodes (NN) was noted (every three days), besides the phenology (every three days) according to the phenological scale suggested by Fehr and Caviness (1977), leaf area (every fifteen days), date of emission and death of every leaf on the main stem (every three days) and the productivity components (in stages R2, R5 and R8).
Leaf area index (LAI) was evaluated according to the method used by Richter et al. (2014) in one plant per plot. In order to determine the productivity potential for the different sowing arrangements, the flowers and pods were counted at the R2, R5 and R8 stages based on the methodology of Pires et al. (2005). The length of the cultivar cycle (phenology) was expressed in terms of the thermal sum calculated by the method suggested by Arnold (1960):

(1) $\quad$ (1) When Tb $\leq$ Tmed $\leq$ Tot:

$S T d=(\text { Tmed }-T b)^{*} \quad(1$ day $)$

Or

(2) When Tot $<$ Tmed $\leq$ Tmax:

STd $=(T o t-T b) \times\left(\frac{T \text { max }-T m e d}{T \text { max }-T o t}\right)$

If $\mathrm{Tmed}<\mathrm{Tb}$ then Tmed $=\mathrm{Tb}$; If Tmed $>$ Tmax then Tmed $=$ Tmax

Where; STd is the daily thermal sum total, Tmed refers to the average temperature of the day, and $\mathrm{Tb}$ indicates the lower basal temperature. Tot is the optimal temperature and Tmax the maximum temperature for soybean development. $\mathrm{Tb}=7.6 \hat{\mathrm{A}}^{\circ} \mathrm{C}$, Topt $=31 \hat{\mathrm{A}}^{\circ} \mathrm{C}$ and $\mathrm{Tmax}=40 \hat{\mathrm{A}}^{\circ} \mathrm{C}$ to calculate the thermal sum of the vegetative phase (Seeding-R1), and $\mathrm{Tb}=0.0 \hat{\mathrm{A}}^{\circ} \mathrm{C}$, Topt $=21.5^{\circ} \mathrm{C}$ and $\mathrm{Tmax}=$ $38.7^{\circ} \mathrm{C}$ to calculate the thermal sum of the reproductive phase (R1-R8) (Setiyono et al., 2007). Using the daily thermal sum from sowing, the accumulated thermal sum (STa) was calculated, that is: STa $=\Sigma S T d$

The time period from sowing to the emergence phase (SEM$\mathrm{VE}$ ), emergence to the commencement of flowering (VE-R1), beginning of flowering to the full maturation (R1-R8) and sub-phases R1-R5, R5-R7 and R7-R8 were considered. The time of life of each trifolium on the main stem was calculated as the thermal sum, taking into account the basal temperatures of the vegetative period of the crop, as proposed by Setiyono et al. (2007). This was achieved by calculating the difference from the date of issue of the trifolium to the date of its death, considered when the leaf limb displayed $50 \%$ yellowing. The plastochron of the two cultivars were sown according to the different plant arrangements which calculated by the inverse of the linear regression coefficient between NN and STa (Xue et al., 2004). The leaf senescence curve was assessed by the means of the regression between the senesced NN and STa.

Data on the minimum and maximum daily air temperatures $\left({ }^{\circ} \mathrm{C}\right)$, precipitation, solar radiation and day length during the experimental period were drawn from the conventional meteorological station of the 8th Meteorological Department of the National Institute of Meteorology (DISME / INMET) in Santa Maria, located at roughly $1000 \mathrm{~m}$ from the experimental region (Supplementary Figure 1). The average daily air temperature (Tmed) was estimated from the arithmetic mean of the minimum and maximum temperatures.

\section{Statistical analysis}

The findings were submitted to the analysis of variance by the $F$ test, and the data for each agricultural year were analyzed. When significant differences were identified between the treatments, they were compared by the ScottKnott test to $5 \%$ probability of error employing the SISVAR program (Ferreira, 2011). 
The leaf senescence rate curve observed for the main stem is explained by the 4th degree polynomial model with two peaks in the senescence rate, one during the pre-flowering stage and the other when grain filling was completed.

A lower fixation rate of the reproductive structures was evident in the reduced (29.5\%) and crossed $(28.5 \%)$ spacing for the cultivar BMX Tornado RR and, in the reduced spacing (37.7\%) for the cultivar FPS Urano RR. Interestingly, it was $18.5 \%$ in the reduced spacing for the FPS Urano RR and 9.7 and $13 \%$ in the reduced and crossed spacing for the $\mathrm{BMX}$ Tornado RR.

\section{References}

Arnold CY (1960) Maximum-minimum temperature as a basis for computing heat units. Proceedings of the American Society for Horticultural Science. 76: 682-692.

Balbinot Junior AA, Oliveira MCN, Zucarelli C, Ferreira AS, Werner F, Silva MAA (2018) Analysis of phenotypic plasticity in indeterminate soybean cultivars under different row spacing. Australian Journal Crop Science. 12 (04):648-654.

Bruns HA (2011) Comparisons of Single-Row and TwinRow Soybean Production in the Mid- South. Agronomy Journal. 103 (3): 702-708.

Egli DB (2013) The Relationship between the Number of Nodes and Pods in Soybean Communities. Crop Science. 53:1668-1676.

EMBRAPA (2014) Indicações técnicas para a Cultura da Soja no Rio Grande do Sul e em Santa Catarina, safras 2014/2015 e 2015/2016. Pelotas, RS. 124

EMBRAPA (2013) Sistema brasileiro de classificação de solos. 3rd edn. Brasília, DF. 353

Fehr WR, Caviness CE (1977) Stages of soybean development. Ames: lowa State University of Science and Technology, 3: 15-27.

Ferreira DF (2011) Sisvar: a computer statistical analysis system. Ciência e Agrotecnologia. 35: 1039-1042.

Ferreira AS, Zucareli C, Werner F, Balbinot Junior AA(2018) Plant spatial arrangement affects grain production from branches and stem of soybean cultivars. Bragantia. 77 (4): 567-576.

Jaybhaye PR, Shinde PB, Asewar BV (2015) Response of soybean to sowing dates and spacing under rainfed condition. International Journal of Tropical Agriculture. 33: 747-750.

Kantolic AG, Mercau JL, Slafer GA, Sadras VO (2007) Simulated yield advantages of extending post-flowering development at the expense of a shorter pre-flowering development in soybean. Field Crops Research. 101: 321-330.

MAPA, Ministério da Agricultura, Pecuária e Abastecimento (2015) Zoneamento Agrícola de Risco Climático para a cultura de soja no Estado do Rio Grande do Sul, ano-safra 2014/2015. Portaria no 179, de 4 de agosto de 2015. Brasília, DF.

Nico M, Miralles DJ, Kantolic AG (2015) Post-flowering photoperiod and radiation interaction in soybean yield determination: Direct and in direct photoperiodic effecs. Field Crops Research. 176: 45-55.
Ookawa T, Tomita N, Hirasawa T (2005) Interaction of scion and stock on leaf senescence of soybean plants grafted at mid-stem during ripening. Plant Production Science. 8: 32-37.

Peel MC, Finlayson BL, McMahon TA (2007) Updated world map of the Koppen-Geiger climate classification. Hydroly Earth System Sciences. 11: 1633-1644.

Pires JLF, Costa JA, Rambo L, Ferreira FG (2005) Métodos para a estimativa do potencial de rendimento da soja durante a ontogenia. Pesquisa Agropecuária Brasileira. 40: 337-344.

Procópio SO, Junior AAB, Debiasi H, Franchini JC, Panison F (2014) Semeadura em fileira dupla e espaçamento reduzido na cultura da soja. Revista Brasileira de Agroambiente. 8: 212-221.

Rahman MM, Rahman MM, Hossain MM (2013) Effect of Row Spacing and Cultivar on the Growth and Seed Yield of Soybean (Glycine max [L.] Merrill) in Kharif-II Season. The Agriculturists. 11: 33-38.

Richter GL, Zanon Júnior A, Streck NA, Guedes JVC, Kräulich B, Rocha TSMD, Cera JC (2014) Estimating leaf area of modern soybean cultivars by a non-destructive method. Bragantia. 73: 416-425.

Rocha TSMD, Streck NA, Zanon AJ, Marcolin E, Petry MT, Tagliapietra EL, Bexaira KP (2017) Performance of soybean in hydromorphic and nonhydromorphic soil under irrigated or rainfed conditions. Pesquisa Agropecuária Brasileira. 52: 293-302.

Santos RF, Bassegio D, Boareto B, Secco D, de Souza SNM, da Silva TRB (2015) Cultivation of soybean varieties under cross-seeding system. African Journal of Agricultural Research. 10: 404-407.

Setiyono TD, Bastidas AM, Cassman KG, Weiss A, Dobermann A, Specht JE (2011) Nodal leaf area distribution in soybean plants grown in high yield environments. Agronomy Journal. 103: 1198-1205.

Setiyono TD, Weiss A, Specht J, Bastidas AM, Cassman KG, Dobermann A (2007) Understanding and modeling the effect of temperature and daylenght on soybean phenology under high-yield conditions. Field Crops Research. 100: 257-271.

Sinclair TR, Neumaier N., Farias JRB, Nepomuceno AL (2005) Comparsion of vegetative development in soybean cultivars for low-latitude environment. Field Crops Reserch. 92: 53-59.

Souza RTG, Teixeira IR, Jesus FF, Reis EF (2017) Spray droplet spectrum and spray deposition in different soybean sowing systems. Australian Journal Crop Science. 11(09):1195-1202.

Tagliapietra EL, Streck NA, Rocha TSM, Richter GL, Silva MR, Cera JC, Guedes JVC, Zanon AJ (2018) Optimum Leaf Area Index to Reach Soybean Yield Potential in Subtropical Environment. Agronomy Journal. 110: 1-7.

Taiz L, Zeiger E, Moller IM, Murphy A (2017) Physiology and Plant Development. 6nd eds. Artmed, Porto Alegre, 888p.

Xue Q, Weiss A, Baezinger PS (2004) Predicting leaf appearance infield grown winter wheat: evaluating linear and non - linear models. Ecological Modelling. 175: 261-270.

Zanon AJ, Winck JEM, Streck NA, Rocha TSM, Cera JC, Richter GL, Marchesan E (2015) Desenvolvimento de 
cultivares de soja em função do grupo de maturação e tipo de crescimento em terras altas e terras baixas. Bragantia. 74: 400-411.

Zanon AJ, Streck NA, Grassini P (2016) Climate and management factors influence soybean yield potential in a subtropical environment. Agronomy Journal. 108(4): 1447-1454.
Zhou XB, Chen YH, Ouyang Z (2011) Row spacing effect on leaf area development, light interception, crop growth and grain yield of summer soybean crops in Northern China. African Journal of Agricultural Research. 6: 1430-1437. 